\title{
UM OLHAR PARA O EFEITO-TEXTO: A MUDANÇA DA POSIÇÃO- SUJEITO DA ESCRITA À REESCRITA DE TEXTOS NA UNIVERSIDADE
}

\author{
A LOOK AT THE TEXT-EFFECT: THE CHANGE IN SUBJECT POSITION FROM \\ WRITING TO REWRITING OF TEXTS AT UNIVERSITY
}

\author{
Aline Juchem ${ }^{1}$ \\ "A tarefa do analista do discurso é expor a opacidade do texto ao olhar do leitor". \\ Michel Pêcheux, Por uma análise automática do discurso
}

\begin{abstract}
RESUMO: O objetivo deste trabalho é discutir a mudança de posição-sujeito no processo de escrita e reescrita de textos no contexto acadêmico. A partir da perspectiva da Análise do Discurso de base pecheutiana, cuja unidade de análise é o texto, busca-se lançar um olhar para o efeito da relação entre sujeito-língua-história, visto que o ponto de vista do analista do discurso não visa a desvendar o que o texto quer dizer, mas como o texto significa. Desse modo, considera-se que o sentido do texto é efeito de um processo de significação, que, neste trabalho, se instaura entre a escrita e a reescrita de textos na universidade, a partir do qual se tecem os sentidos do discurso emergidos pelo efeito-texto. Da escrita à reescrita, o aluno (re)inscreve-se na inter-relação entre sujeito-língua-história, que se manifesta no texto, e revela uma mudança de "tomada de posição" - pela qual o sujeito se contrapõe aos saberes organizados no interior de determinada formação discursiva -, desconstruindo-os $e$ reconstruindo-os no processo de subjetivação da reescrita. Nesse espaço de ressignificação discursiva, os sentidos se repetem e se deslocam para outros sentidos, para novas posições na linguagem, e esse olhar significa o estudo do texto em sala de aula.
\end{abstract}

PALAVRAS-CHAVE: efeito-texto; posição-sujeito; escrita e reescrita; análise do discurso.

\begin{abstract}
This academic paper aims to discuss the subject position change in the process of writing and rewriting texts in the academic context. From the pecheutiana Analysis discourse perspective, whose unit of analysis is the text, it's sought to understand the effect of the relation between subject-language-history, since discourse analyst's point of view does not aim to discover what a text is, but rather what it means. Thus, we considered that the meaning of a text is an effect of the signification process, which, in this study, is established between writing and rewriting texts at university, from which emerges the meanings of discourse through the text-effect. From writing to rewriting, the student is (re)inscribed in the interrelation between subject-language-history that is manifested in the text, and reveals a change of "positioning" - by which the subject is opposed to the organized knowledge within a certain discursive formation -, deconstructing them and reconstructing them in the process of subjectification of the rewriting. In this space of discursive resignification, the meaning are repeated and moved to other senses, to new positions in language, and this look means the study of the text.
\end{abstract}

\footnotetext{
${ }^{1}$ Doutora em Letras pela Universidade Federal do Rio Grande do Sul (UFRGS) e Professora Substituta do Departamento de Letras Clássicas e Vernáculas do Instituto de Letras da UFRGS, na área de Língua Portuguesa.
} 
KEYWORDS: text-effect; subject position; writing and rewriting; discourse analysis.

\section{Palavras iniciais: o olhar do analista de linguagem (e do professor)}

A origem de escrita deste trabalho se dá em razão de uma necessidade: a de o professor, enquanto analista de linguagem, ampliar o olhar que dedica ao estudo do texto e do discurso, enquanto objetos teóricos. Especificamente, aqui, a ótica teórica ajusta seu ângulo sob a Análise do Discurso, concebida numa perspectiva discursiva materialista, centrando seus estudos nas condições de produção do discurso, pelas quais compreendemos um sujeitoautor (o aluno) que escreve aquilo que pode ser pensado, tendo em vista que ele está inserido num conjunto de possibilidades de dizer.

Ressalta-se que, dentre as diferentes perspectivas voltadas aos estudos linguagem, a perspectiva discursiva - vertente importante para a abertura e o diálogo com outros campos, como a Linguística Textual - serve ao propósito desta pesquisa, que é refletir sobre a mudança de posição-sujeito no processo de escrita e reescrita de textos na Universidade, uma vez que se entende que, na/pela língua, o sujeito se inscreve simbolicamente no mundo e na história. A partir de conceitos norteadores tais como história, historicidade, formação discursiva, formação ideológica, interdiscurso, posição-sujeito, pretende-se discutir de que modo eles se manifestam no processo discursivo do sujeito-aluno, inscrito na sala de aula universitária, cuja cultura se manifesta na apropriação da língua pelo sujeito, justamente porque se considera a exterioridade integrante da linguagem, ou seja, não há uma exterioridade senão aquela construída e manifesta na linguagem.

Como ponto de partida da orientação teórico-metodológica, consideramos a fala de um aluno do primeiro semestre de Graduação, do curso de Engenharia Cartográfica, bastante significativa, justamente pelos diferentes olhares de sentido que podem ser lançados sobre ela pelo analista de linguagem: "Quando escrevo uma redação, não consigo me enxergar nela, mas quando escrevo no MSN ${ }^{2}$ até meus amigos sabem que sou quem está escrevendo". 3

Esta fala, particularmente expressiva quanto ao modo de o aluno conceber a função da escrita de uma "redação" - gênero do discurso comumente atribuído à escola e às formas de avaliação institucionais -, é oriunda do primeiro dia de aula no Programa de Apoio à

\footnotetext{
${ }^{2}$ A sigla $M S N$ se refere ao programa virtual de bate-papo Messenger.

${ }^{3}$ Este corpus já foi utilizado para análise pela perspectiva enunciativa benvenistiana em Juchem (2012). Em razão do interesse particular pelo processo de escrita e reescrita de textos, busca-se ampliar as perspectivas teórico-metodológicas acerca de tal objeto teórico, tendo em vista a necessidade de ampliação do olhar do professor, enquanto analista de linguagem, voltado ao estudo do texto e do discurso, enquanto objeto teórico multifacetado.
} 
Graduação - Projeto de Leitura e Produção de Textos em Língua Portuguesa (PAG-LP) ${ }^{4}$ da Universidade Federal do Rio Grande do Sul, antes do contato do aluno com a primeira proposta de produção de textos. A proposta metodológica do PAG-LP é baseada no eixo usoreflexão-uso, pelo qual entende o ensino-aprendizagem de textos enquanto um processo: a) o aluno produz o texto escrito para que, na aula seguinte, ele seja lido em voz alta para professor e colegas; b) a partir da escuta e da percepção, professor e colegas atribuem ao texto lido comentários sobre suas impressões acerca das referências produzidas pelo aluno na leitura pública; c) em momento posterior, o aluno produz a (re)escrita do texto, com base nos comentários de seus ouvintes e "leitores".

A partir do eixo escrita-leitura-(re)escrita, busca-se, neste artigo, proceder à análise de dois textos de um mesmo aluno, a escrita e a reescrita, produzidos com base na primeira proposta de produção de textos: A minha presença na Universidade.

Do ponto de vista teórico-metodológico, o que está em questão na análise dos dois textos é o que subjaz ao discurso, ou ainda, o seu funcionamento e como ele produz sentidos. Se "o discurso é uma dispersão de textos e o texto é uma dispersão do sujeito" (ORLANDI, 2007a, p. 70), é no texto, enquanto materialidade linguística e materialidade históricadialética, que está a produção de sentidos e a sua relação com a exterioridade - uma exterioridade integrante -; e se é assim, então os sentidos não têm fim. Ademais, se o discurso é uma dispersão de textos, é porque neles "não encontramos apenas uma formação discursiva, o texto pode ser atravessado por várias formações discursivas que nele se organizam em função de uma dominante", conforme a autora (2007a, p. 71).

Nessa perspectiva, o texto é uma unidade de análise, um efeito-texto; enquanto o discurso, um objeto de análise - e, por isso, o olhar deve ser multifacetado, já que se trata sempre de um texto-discurso. Dessa correlação, chega-se ao objeto de reflexão, que é o interdiscurso, a formação discursiva na qual se inscreve o sujeito-aluno, a partir da qual se pode observar e delimitar o grupo de enunciados que pertencem a essa formação, chegando ao corpus discursivo, cujo recorte é fundamental, segundo Mittmann (2007).

Do ponto de visto analítico, o texto não é o ponto de partida nem o de chegada; é tão somente a via de acesso ao discurso, e o que se tem como produto de análise é a compreensão dos processos de produção de sentidos e de constituição das posições do sujeito. Ou seja, o que interessa, na análise, é “como o texto organiza a relação da língua com a história no

\footnotetext{
${ }^{4}$ Projeto do qual fiz parte como professora-bolsista de mestrado pela CAPES-REUNI, de março de 2010 a março de 2011, e de doutorado pela CAPES-Demanda Social, de 2013 a 2015.

${ }^{5}$ O cerne dessa metodologia é fruto das pesquisas de Autor $(2012,2017)$ sob a perspectiva da Teoria da Enunciação.
} 
trabalho significante do sujeito em sua relação com o mundo" (ORLANDI, 2007a, p. 69). Para a autora, são os fatos que nos permitem chegar à memória da língua e, desse modo, compreender como o texto funciona enquanto objeto simbólico. É desse olhar que partimos.

\section{Do ponto de vista teórico: no curso da análise}

Ao recuperar a fala do aluno, citada anteriormente, percebemos que esta revela um gesto de leitura, ou melhor, de interpretação com relação às possibilidades da inscrição do sujeito que determinados discursos permitem. Esse gesto de interpretação diz sobre este sujeito-aluno, pois é nesse processo que ele revela sua autoria. A autoria é, nesse ponto, o próprio processo de interpretação, e nos leva a duas implicações convergentes: a primeira é de que, no funcionamento do discurso, o sujeito marca sua relação com o mundo, isto é, revela pelo discurso sua relação com a exterioridade - sócio histórica -; e, a segunda, é de que o sujeito está representado no texto por uma função-autor, em que se constrói sua unidade como sujeito. Para Orlandi:

Há na base de todo discurso um projeto totalizante do sujeito, projeto que o converte em autor. $\mathrm{O}$ autor é o lugar em que se realiza esse projeto totalizante, o lugar onde se constrói a unidade do sujeito. Como o lugar da unidade é o texto, o sujeito se constitui como autor ao constituir o texto em sua unidade (2007a, p. 73).

Essa função-autor - função discursiva do sujeito - caminha ao lado de funções enunciativas, como explica Orlandi a exemplo de Foucault:

\footnotetext{
se o locutor se representa como eu no discurso e o enunciador é a perspectiva que esse eu assume, a função discursiva autor é a função que esse eu assume enquanto produtor de linguagem, produtor de texto. Ele é, das dimensões do sujeito, a que está mais determinada pela exterioridade - contexto socio histórico - e mais afetada pelas exigências de coerência, não contradição, responsabilidade etc. Sendo a autoria a função mais afetada pelo contato com o social e com as coerções, ela está mais submetida às regras das instituições e nela são mais visíveis os procedimentos disciplinares (ORLANDI, 2007a, p. 75).
}

Como autor, o sujeito, ao mesmo tempo em que reconhece a exterioridade à qual deve se referir, refere também a si mesmo. Segundo Orlandi (2007a), o autor é "o sujeito que, tendo domínio de certos mecanismos discursivos, representa, pela linguagem, esse papel na ordem em que está inscrito, na posição em que se constitui, assumindo a responsabilidade pelo que diz, como diz etc.”. A assunção da autoria implica, assim, a inserção do sujeito na cultura, sua posição no contexto sócio histórico. 
A autoria, sendo uma função afetada pelo social, está submetida às suas regras, à uma formação ideológica dominante, pela qual o sujeito deve se colocar em seu dizer em relação a elas, pois dele se exige uma coerência, uma não-contradição, uma unidade que permitam visualizá-lo em seu discurso, ou melhor, em seu texto. Enquanto o sujeito é marcado pela opacidade e heterogeneidade, o autor deve marcar-se como uma direção argumentativa, assumindo seu dizer, num trabalho de apagamento das marcas de exterioridade, numa costura invisível. Essa articulação permite o trabalho entre exterioridade e interioridade do sujeitoautor.

Nesse ponto, Orlandi (2007a, p. 76) introduz o "polo correspondente", que é o leitor, pois este, imerso na cultura, também é afetado pela história e pelo social, o que, consequentemente, determina seu gesto de leitura. Dele o sujeito-autor espera um diálogo que concorra na mesma direção, uma vez que ambos estão implicados, neste caso, em uma mesma formação discursiva em dado momento do discurso. É na formação discursiva que o interdiscurso se materializa, atravessando o texto e fazendo com que o leitor preencha as lacunas pela memória discursiva.

Desse modo, podemos dizer que o texto, pela função-autor, é uma versão que administra a dispersão das possíveis versões. Pela função-leitor se dá o reconhecimento entre essas versões, num gesto de interpretação, possível pelo direcionamento de sentidos na presença ou mesmo no silenciamento ${ }^{6}$ do texto. O leitor é um efeito porque está no universo dos sentidos possíveis do interdiscurso. Assim, o efeito de sentido é da ordem do equívoco, porque não existe jamais sentido pré-fixado nem intencional; somente construído em relação a outros sentidos.

Esses sentidos constituídos ao longo da história ao qual não temos acesso, que necessariamente "esquecemos" "mas que nos falam e significam, é o interdiscurso, a memória discursiva. Esses sentidos retornam e, ao mesmo tempo, são (re)significados - os sentidos são produzidos em relação aos sentidos já dados dentro de uma formação discursiva.

E o que se concebe por formação discursiva? Considerando sinteticamente a concepção de Pêcheux (1988), formação discursiva corresponde a um domínio de saber constituído de enunciados discursivos relacionados à ideologia vigente, que regula aquilo que pode e deve ser dito. À ideologia vigente Pêcheux atribui a noção de Forma-sujeito, como o

\footnotetext{
${ }^{6}$ Para Orlandi (2007b, p. 84) o que não é dito, ou seja, o que é silenciado constitui igualmente o sentido do que é dito, uma vez que o silêncio atravessa a linguagem.

${ }^{7}$ Conforme a mesma autora, o esquecimento é o apagamento necessário de sentido de uma materialidade linguística, no caso, de uma palavra, para que ela possa ressignificar, isto é, constituir outro sentido pelo conjunto de formações discursivas dominante.
} 
saber histórico em que circulam as formas-sujeito, as formações discursivas como o espaço da contradição. Desse modo, pode-se dizer que as palavras não derivam sentidos próprios; pelo contrário, as palavras estão à deriva dos sentidos, sob a determinação de formações discursivas nas quais se inscrevem. As palavras sempre falam com outras palavras já-ditas, e só por isso significam.

É pela língua que a ideologia se materializa, uma vez que os sentidos se sedimentam na história. O indivíduo nasce na ideologia e por ela é inscrito em uma formação discursiva; logo, o homem é interpelado em sujeito ideologicamente. Para Althusser (1999), “a ideologia é uma 'representação` da relação imaginária dos indivíduos com suas condições reais de existência" visível por práticas circunscritas à existência material dos aparelhos ideológicos de Estado (AIEs), que, segundo o autor, são um certo número de realidades apresentadas sob a forma de instituições distintas e especializadas - escolar, religiosa, familiar, jurídica, política etc. Para ele, a formação discursiva está na relação entre a história, as práticas sociais (ideologia) e a materialidade linguística. A ideologia não existe fora das realidades materiais concretas.

Nesse sentido, o discursivo é somente um dos aspectos materiais da materialidade ideológica. Outros aspectos são as práticas, os rituais, os saberes que correspondem às instituições. Assim, o gênero discursivo se inscreve em um gênero ideológico, segundo Pêcheux (1975, p. 233), o que leva a correlacionar a fala do aluno à posição-sujeito que ocupa com relação ao gênero no qual se inscreve, a redação. Aparece, aqui, a interpelação do sujeito pela ideologia em dois níveis: a interpelação em sujeito pela história - em que a relação com o outro se dá a nível inconsciente - e pela ilusão de que, ao se enunciar, o sujeito é fonte do seu dizer e dos sentidos - em que a relação com o outro (empírico) se dá a nível consciente -, quando, na verdade, o discurso "fala antes" 8.

Nessa direção, Pêcheux se distancia de Althusser ao refletir acerca das relações entre formação ideológica e formação discursiva. No interior de uma formação ideológica pode-se ter mais de uma formação discursiva; é no complexo da formação ideológica e na identidade com as formações discursivas que há a interpelação do indivíduo em sujeito. Mais especificamente: a interpelação do sujeito se dá pela identificação com a formação discursiva na qual se inscreve (PÊCHEUX, 1988, p. 163). Ou ainda, "é o indivíduo que, interpelado pela ideologia, se constitui como sujeito, identificando-se com os dizeres da formação discursiva

\footnotetext{
${ }^{8}$ Pêcheux (1988) vai chamar esse processo de interpelação de efeito Münchhausen, uma vez que o sujeito resulta de um processo de interpelação-constituição pela ideologia, sendo efeito do apagamento necessário desse processo como sendo ele a origem do discurso, a "causa de si".
} 
que representa, na linguagem, um recorte da formação ideológica” (INDURSKY, 2007, p. 79, grifo meu).

Visto desse modo, a língua não é, portanto, só materialidade linguística, mas materialidade histórica e dialética, uma vez que a língua é socialmente marcada - não há como dissociar o que está dentro e o que está fora, pois a exterioridade integra a língua. E considerar a língua como social implica considerar sua historicidade, que não é cronológica, e, sim, o processo de inscrição da língua na história, através do qual ela significa. Segundo Orlandi, a historicidade está "no confronto que sujeitos/sentidos tecem no interior de uma formação discursiva a partir das diferentes posições em que se inscrevem e também no embate entre diferentes formações discursivas" (2001, p. 156), sendo impossível separar o que é interno ou externo ao texto, pois ela é constitutiva da produção de sentidos. ${ }^{9}$

Nesse processo importam ainda as condições de produção inscritas na língua, consideradas em sentido estrito - o contexto imediato - ou em sentido amplo - contexto sócio histórico (ORLANDI, 2007a, p. 30), nas quais estão implicadas as relações de sentido, as relações de força e a antecipação. O primeiro tipo de relação resulta do diálogo entre discursos, que determina o que foi e o que será dito; o segundo, de relações de poder, hierarquizadas socialmente, que designam as posições do sujeito no discurso. Dessa forma, não são os sujeitos físicos nem seus lugares empíricos que funcionam no discurso, mas as projeções que resultam dessas relações. Por essas projeções que é possível ao sujeito passar de lugar empírico para a posição discursiva. E o que significa no discurso são as posições de sujeito $^{10}$.

Assim, do ponto de vista da análise, o lugar que o aluno ocupa na escrita e, depois, na reescrita é aquele a que Pêcheux $(1975$, p. 232) se refere como "representação da relação imaginária”, sobre o que se entende que o lugar social está determinado pelo real vivido. A posição do sujeito está, pois, em relação ao lugar que ocupa e aquele imaginado que o outro ocupa. Quanto às posições de sujeito e à formação discursiva - noções que se implicam mutuamente neste quadro teórico -, Pêcheux tem o mérito de pensar a contradição. Relativizando a questão de identificação plena do sujeito com a Forma-sujeito (FI), já abordada, o autor introduz as modalidades de subjetivação, ou "modalidades de tomada de

\footnotetext{
${ }^{9}$ A autora ainda chama a atenção para o ponto de vista da historicidade do texto, e não no texto, pois o que está em questão não é o sentido da unidade-texto, mas como ele produz o sentido.

${ }^{10}$ Parece importante frisar que "sujeito" não é tomado aqui como sujeito empírico, mas como constructo teórico, um sujeito de consciência, dividido em posições de sujeito. O termo consciência resguarda uma concepção importante, pois, visto à luz de Bakhtin (Volochinov), desmistifica a concepção psicologizante de uma consciência individual do sujeito; ao contrário, a consciência é de ordem sociológica: "a consciência adquire forma e existência nos signos criados por um grupo organizado no curso de suas relações sociais” (BAKHTIN (Volochinov), 1986, p. 35).
} 
posição", representando aquilo que Courtine (2009, p. 102) vai chamar de sujeito-dividido, o conjunto das diferentes posições de sujeito em uma FD com modalidades particulares de identificação.

Para Pêcheux (1988), as posições de sujeito são designadas em: o "bom sujeito", o "mau sujeito" e a "desidentificação". A primeira revela a identificação plena do sujeito com a formação discursiva na qual se inscreve, uma "superposição" ou, ainda, uma "reduplicação da identificação". A segunda modalidade, ao contrário, revela uma "tomada de posição", pela qual o sujeito se contrapõe aos saberes organizados no interior da formação discursiva; por isso, o "mau sujeito" ou “contra identificação". Nesse sentido, Indursky (2007, p. 80) complementa:

\begin{abstract}
cabe frisar, de imediato, que esta tensão entre a plena identificação com os saberes da FD e a contra identificação com os mesmos saberes ocorre no interior da FD, ou seja, o sujeito do discurso questiona saberes pertencentes à formação discursiva em que ele se inscreve e o faz a partir do interior desta mesma formação discursiva. Isto é: a contra identificação é um trabalho do sujeito do discurso sobre os dizeres e os sentidos que são próprios à FD que o afeta e, por conseguinte, se institui como forma de resistência à forma-sujeito e ao domínio de saberes que ela organiza.
\end{abstract}

Sendo assim, pode-se compreender que, em uma mesma formação discursiva, há várias posições-sujeito. Tomando como base essas modalidades, é possível entender o espaço da contradição no seio da formação discursiva. É a contra identificação, segundo Indursky (2007, p. 83), que introduz a diferença, a divergência, a possibilidade de ressignificar. E isso remonta à questão da interpelação: os sentidos estão à deriva, podem ser questionados e se tornarem outros. Essa é a falha no ritual, no momento de encontro do sujeito do discurso com a linguagem e a história, cuja consequência é a instauração de uma nova posição-sujeito, que introduz na formação discursiva na qual estava inscrito novos saberes, transformando-a ou reconfigurando-a.

\title{
Do ponto de vista analítico: a posição-sujeito da escrita à reescrita de textos na Universidade
}


Ao dedicar agora o olhar à escrita do aluno, conforme Figuras 1 e 2, a seguir, é possível identificar a formação discursiva na qual o sujeito está inscrito através do enunciado estou cursando o primeiro semestre de Engenharia Cartográfica.

Essa formação discursiva pode ser fragmentada em: uma formação discursiva de acordo com o curso de escolha pelo aluno, no qual reúne uma "família de discursos" própria que a caracteriza; uma formação discursiva de alunos ingressantes na universidade federal; e uma de alunos que procuram o projeto de leitura e de produção de textos devido à dificuldade que sentem em relação à escrita ${ }^{11}$. A escrita sempre se funde em uma formação discursiva, mas esta faz parte de uma formação ideológica que a regula, no caso, a escola (AI).

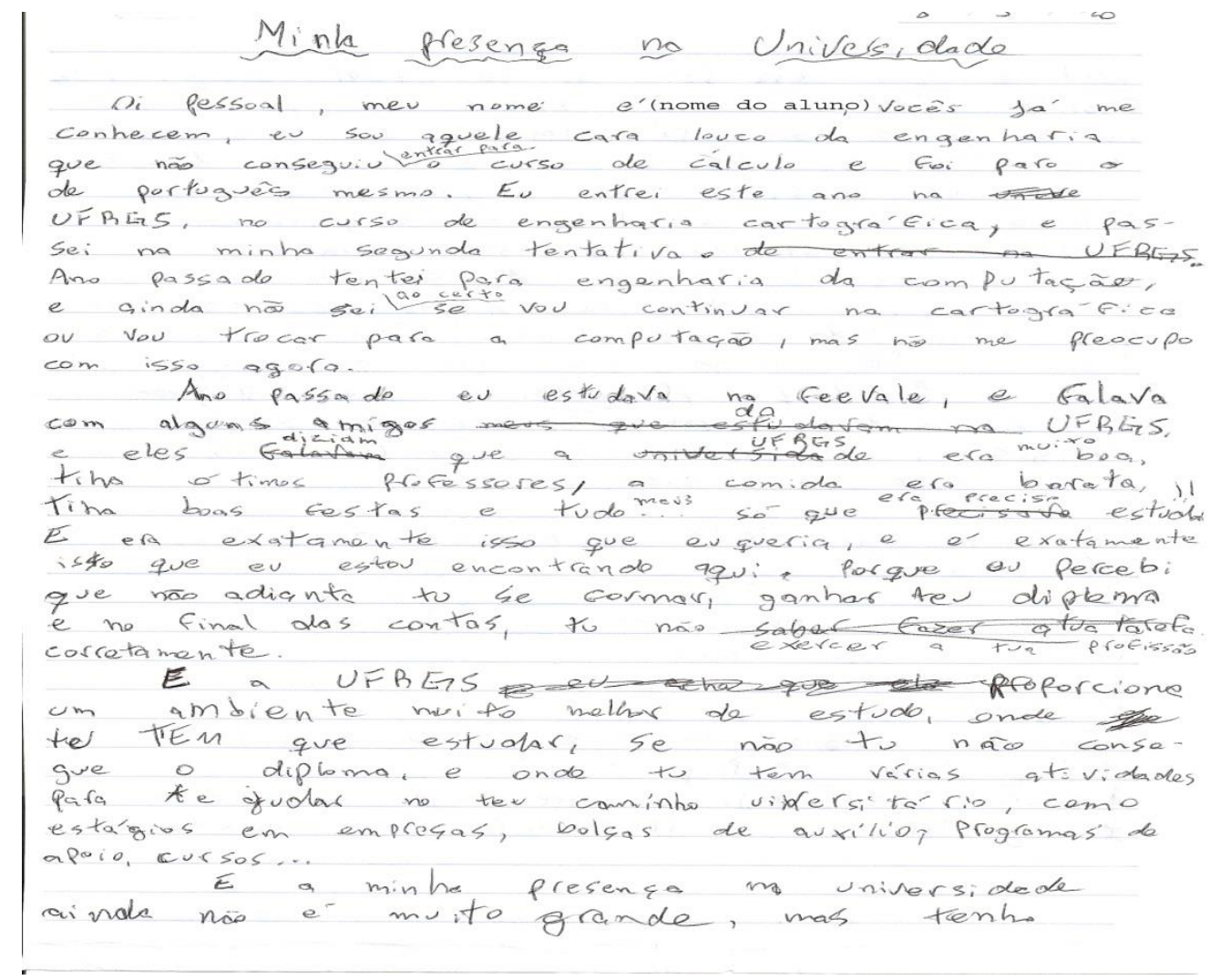

Figura 1: Escrita do texto (primeira página).

\footnotetext{
${ }^{11}$ O PAG-LP é oferecido aos alunos de graduação ingressantes que tiveram um escore inferior a 16 na prova de redação e de português no vestibular. Mas vale mencionar que mesmo alunos não-ingressantes também procuraram o projeto pela necessidade de um aprimoramento no uso da língua portuguesa na leitura e na escrita.
} 


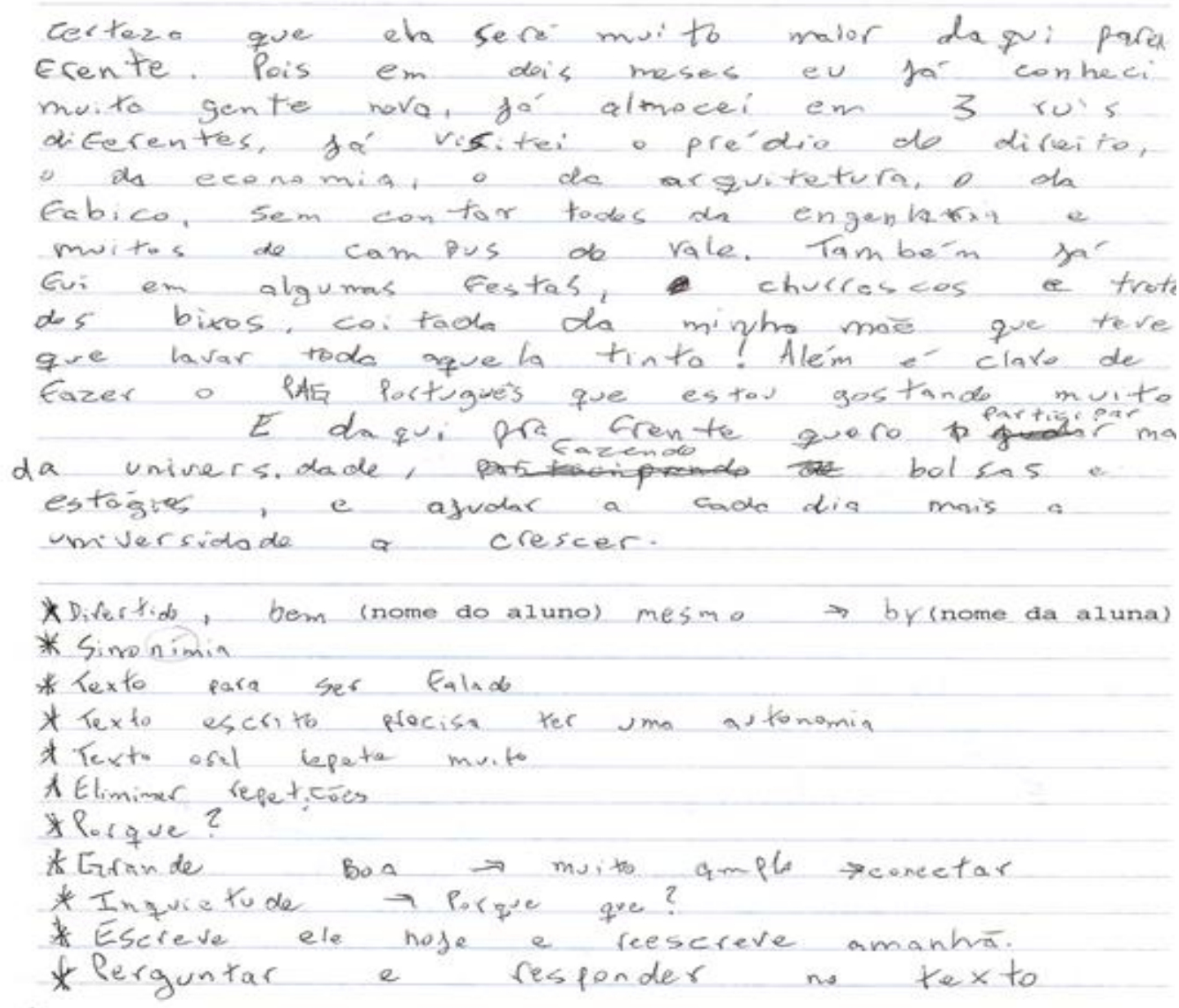

Figura 2: Escrita do texto (segunda página).

$\mathrm{Na}$ análise do primeiro texto, percebe-se a posição discursiva do sujeito, de um aluno ingressante e "deficiente" na escrita à procura de um espaço na produção de textos. Em alguns enunciados, é possível identificar discursos pré-construídos (interdiscurso), por exemplo, em: a primeira impressão que eu tive é que ela é no mínimo grande, vi que ela tinha boas salas de aula (etc.); ela ajuda (muito) na questão financeira, como os RU's, o desconto nas passagens, as casas de estudantes...; os professores aqui da universidade têm que ter doutorado para dar aula; e esse foi um dos motivos para estudar em uma universidade federal, porque além de ser de graça, o ensino dela é muito mais avançado e o aluno tem que estudar muito mais para formar-se...

Esses enunciados são atravessados por pré-construídos que falam justamente por uma “ausência”, por aquilo que os subjazem, que não está dito ou está negado, mas significam - e significam em relação a uma exterioridade que integra esses enunciados. Ao analisa-los, constata-se que todos estão em relação a uma concepção de universidade federal comparada a outros tipos de instituições, como a particular (mencionada na reescrita); porém, a questão não é o julgamento de valor de uma instituição em relação à outra, mas a ideologia que as 
constitui nos discursos. A comparação não é relevante enquanto fato concreto, mas, sim, como indício de como a ideologia afeta o discurso desse sujeito-aluno.

Em outros enunciados, como eu acredito que um diploma não serve para nada se tu realmente não aprendeu nada com o que lhe foi ensinado; e eu não quero ser apenas um bom engenheiro, mas acima de tudo um bom engenheiro, já apontam para uma rede de discursos que circulam além do âmbito escolar; estão em relação a uma "realidade maior" em que ter um diploma não significa ter apreendido nem ter competência na profissão pela formação acadêmica.

No enunciado meu nome é (nome completo), é interessante notar que o aluno carrega um pré-construído que justifica sua fala inicial, pois ele lida com os acontecimentos a partir do lugar das forças sociais, ou seja, o sujeito-aluno faz a história nas condições que a história lhe permite fazer, no caso, inscrever - escrever. Se "as formas do signo são condicionadas tanto pela organização social de tais indivíduos como pelas condições em que a interação acontece. Uma modificação destas formas ocasiona uma modificação do signo" (BAKHTIN/VOLOCHINOV, 1986, p. 44), aqui os signos são tomados como os gêneros redação e $M S N$, visto cada um assumir um valor de ordem simbólica e histórica. O gênero, pois, é discursivo no momento em que é socialmente direcionado e, por isso, ideologicamente constituído. É dentro da formação discursiva que esse signo toma sentido próprio.

Essa posição-sujeito depende, então, do lugar do qual fala o sujeito-aluno, que não é físico nem empírico, mas sua inscrição na sociedade, na história e no discurso. Esse lugar, como já vimos, é determinado por relações de força que atribuem hierarquia aos lugares dos quais se fala, isto é, o sujeito-aluno fala como aluno considerando seus interlocutores (a equipe docente, primeiramente, e os colegas), sendo essa relação constitutiva do que ele diz. Mais uma vez, o efeito de sentido desse discurso depende dos lugares sociais ocupados - das posições-sujeito - e não da situação, conforme ensina Pêcheux (1975).

O aluno escreve ainda na expectativa de um leitor "indiferente", ou "transparente", o que se revela em sua fala pela memória institucionalizada do processo de escrita do gênero redação, na qual parece carecer a figura de um leitor presente ou efetivo. $\mathrm{O}$ aluno "reduz o interlocutor ao silêncio", nas palavras de Orlandi (2007b, p. 41), a respeito de uma política do silêncio que, a partir da posição de sujeito da qual fala, permite dizer uma coisa para não dizer outras.

Já, no segundo texto, na reescrita, conforme Figura 3, percebe-se um movimento diferente. Parece haver, em relação ao primeiro, o efeito de uma presença "mais concreta" da posição-sujeito/aluno na universidade. 
Oi, meu nome é (nome do aluno), eu tenho 19 anos, entrei este ano na UFRGS na minha segunda tentativa, no curso de Engenharia Cartográfica. Escolhi este curso só porque ele é noturno e a média é baixa, assim já tinha grandes chances de passar, e ainda conseguir trabalhar e estudar aqui em Porto Alegre. Ano passado tentei para Engenharia da Computação, porque sempre gostei de computadores e informática, mas nesse semestre aprendi muito sobre o curso de cartografia, e achei muito interessante a parte de satélites e GPS. Ainda não sei ao certo se vou continuar na cartografia ou vou trocar para a computação, mas não me preocupo com isso agora.

Ano passado eu estudava na Feevale e falava com alguns amigos meus da UFRGS Todos diziam que a UFRGS era muito boa, tinha ótimos professores, a comida era barata, tinha boas festas e boa infraestrutura... só que era preciso estudar! E era exatamente isso que eu queria, e é exatamente isso que eu estou encontrando aqui. Porque eu percebi que não adianta tu se formar, ganhar teu diploma, e no final das contas, tu não ser um bom profissional.

E a UFGRS propicia um ambiente muito melhor de estudo, onde tu tens que estudar se não tu não passas mesmo, e onde tu tens várias atividades para te ajudar no teu caminho universitário, como estágios em empresas, bolsas de auxílio, programas de apoio, cursos, etc.

A minha presença em si na universidade ainda não é muito extensa, mas tenho certeza que ela será muito maior daqui para frente. Pois em poucos meses eu conheci muita gente nova, já almocei em três RU's diferentes, já visitei vários prédios, como o do direito, da economia, da arquitetura, da fabico, da veterinária, sem contar muitos da engenharia do centro e do vale. Também fui a algumas festas, churrascos e trotes de bixos. Além é claro de fazer o PAG Português que estou gostando muito.

E daqui para frente quero participar mais da universidade, fazendo estágios e participando de bolsas, ajudando assim a cada dia mais a universidade a crescer.

Figura 3: Reescrita do texto (transcrição).

Tal efeito é perceptível pelos enunciados: vocês já me conhecem, em dois meses eu já conheci muita gente nova, já visitei o prédio do direito (etc.); também já fui em festas, churrascos e trotes dos bixos, coitada da minha mãe que teve que lavar toda aquela tinta. $\mathrm{Ou}$ seja, o aluno traz para a escrita o que vivencia concreta e externamente a universidade para justificar sua presença nela, assinalando, pelo discurso, de que modo constitui essa relação.

Em outros exemplos de enunciados, como em passei na minha segunda tentativa, estudava na Feevale e falava com alguns amigos da UFRGS, e eles diziam que a UFRGS era muito boa (etc.);... só que era preciso estudar!; e era isso que eu queria..., o sujeito-aluno indica, por elementos factuais, os pré-construídos que se manifestam em seu discurso. Pelos efeitos de sentido da reescrita, pode-se identificar a expectativa do sujeito-aluno ingressante com relação à concepção construída sobre o espaço universitário, como em era isso que eu queria e é exatamente o que estou encontrando aqui; onde tu tem várias atividades para te ajudar no teu caminho universitário, como estágios em empresas, bolsas de auxílio...

Além desses enunciados, outro efeito importante assinala sua mudança em relação à posição-sujeito: meu nome é (só o primeiro nome); sou aquele cara louco da engenharia que não conseguiu entrar no cálculo e foi para o de português; passei na minha segunda 
tentativa; ano passado tentei para a engenharia da computação, ainda não sei. Primeiro, porque o sujeito-aluno se nomeia somente pelo primeiro nome, ao passo que se permite manifestar, pela função-autor, suas marcas de subjetivação, momento em que se atesta uma abertura do simbólico, daquilo que demonstra o indivíduo sendo interpelado em sujeito, como afirma Orlandi (2007a).

Isso pode ser compreendido pela nova forma como o sujeito-aluno se relaciona com a língua e com as condições de produção, uma vez que, ao desmistificar a sua "impotência" na escrita e a "onipotência" dos seus interlocutores, com os quais passa a manter um novo diálogo - conforme se nota na reescrita -, isso permite que ele tenha uma nova tomada de posição-sujeito, a qual se dá pela mediação da língua. No que concerne ao processo de escrita e reescrita, há, a priori, as formações discursivas de: aluno ingressante; aluno de engenharia; aluno "deficiente" (em razão do projeto); instituição federal de ensino; equipe docente como interlocutor "indiferente"; professores em lugares hierárquicos de saber/poder; colegas de diversos cursos (diversas FDs); gênero redação etc.

No entanto, após o contato do aluno com essas várias formações discursivas, percebese também, pela nova tomada de posição-sujeito, formações discursivas reconfiguradas: aluno ingressante; aluno de engenharia que "pode escrever"; aluno do projeto que "pode se singularizar" no gênero redação (ou qual fosse); instituição de ensino "real"; equipe docente "presente", com a qual mantém diálogo; professores e colegas de outros saberes/cursos que também passam a levar novos saberes às suas FDs; gênero redação como espaço de subjetivação etc. Há uma nova posição-sujeito, porque há uma nova relação com a escrita, possível somente pelo contato com outras formações discursivas. Por isso, a afirmação de Indursky:

\footnotetext{
a reconfiguração de uma FD se dá a partir do interdiscurso. Ou seja: saberes que não fazem parte de uma determinada FD, em um determinado momento e em uma dada conjuntura, passam a integrá-la, aí introduzindo a diferença e a divergência, o que está na origem da constituição heterogênea de qualquer FD. E é aí que as diferentes modalidades de tomada de posição assumem seu papel, produzindo o entrelaçamento entre o mesmo e o diferente, vindo de outro lugar, de outro discurso, de outra FD (INDURSKY, 2007, p. 81).
}

É, portanto, na política do dizer, pela função-autor, que o sujeito-aluno abre, fecha, exclui e inclui sujeitos e sentidos, escorregando e derivando para outros lugares e posições, o que nos atesta que os sentidos e os sujeitos não estão fixados, mas em constante movimento no discurso. Ao que parece, esse movimento só é possível pela mudança de posição-sujeito dentro da mesma formação discursiva (de aluno do projeto em questão), ocasionada pelo 
contato com outras formações discursivas (professores, colegas de outras áreas), as quais interferem e "abrem" as possibilidades do seu dizer.

Isso tudo demonstra que o sujeito não está sozinho na língua e, por conseguinte, no discurso. Ao seu lado caminham outros sujeitos e outros discursos, logo, outros sentidos. É justamente pela falta que o sujeito se preenche no discurso, como tão bem ilustra Orlandi (2007a, p. 53):

\begin{abstract}
Sujeito à falha, ao jogo, ao acaso, e também à regra, ao saber, à necessidade. Assim o homem (se)significa. Se o sentido e o sujeito poderiam ser os mesmos, no entanto escorregam, derivam para outros sentidos, para outras posições. A deriva, o deslize é o efeito metafórico, a transferência, a palavra que fala com outras palavras. Entre o jogo e a regra, a necessidade e o acaso, no confronto do mundo e da linguagem, entre o sedimentado e o a se realizar, na experiência e na história, na relação tensa do simbólico com o real e o imaginário, o sujeito e o sentido se repetem e se deslocam [...] Sujeitos, ao mesmo tempo, à língua e à história, ao estabilizado e ao irrealizado, os homens e os sentidos fazem seus percursos, mantêm a linha, se detêm junto às margens, ultrapassam limites, transbordam, refluem.
\end{abstract}

Assim, a fala inicial do sujeito-aluno traz a contradição, pela qual se pode pensar no funcionamento da sociedade, neste caso, no funcionamento da escrita dentro da sociedade. É por essa contradição que o sujeito se reconhece e reconhece o outro, e é por essa contradição que o sujeito escapa, desliza.

\title{
O efeito-texto e a mudança de posição-sujeito
}

Ainda que o sujeito nasce não seja consciente da ideologia, na qual nasce - visto que só o é a partir dela, e sobre ser o sujeito não questiona -, há sempre uma resistência. Essa resistência é, para Milner (1987), o "furo da língua", ou ainda, o real da língua. Essa resistência está assinalada pelas posições de sujeito, como no "mau sujeito", por exemplo, que deixa de se identificar com a formação discursiva na qual estava inscrito. Na análise, tal caso é passível de identificação pelo fato de que, na reescrita, pelo contato com outras FDs - e dessa forma, com outros saberes -, o aluno desconstrói e reconstrói seus saberes acerca do processo de escrita, o que pode ser identificado pelo processo de subjetivação do segundo texto, ou seja, por uma mudança de tomada de posição: uma nova posição-sujeito.

É por essa razão que se pode dizer que há, em todo discurso, uma permeabilidade discursiva, pois há sempre formações discursivas exteriores que vêm fazer parte de outras FDs, modificando-as e transformando-as. Nesse sentido que Schons (2000) vai fazer uso da metáfora da "teia" para o discurso, pois os "nós" que imbricam e sustentam os discursos anteriores imbricam e sustentam a produção de cada discurso, a partir da memória discursiva, 
ou seja, do interdiscurso, “que aparece como o puro ’já-dito` do intradiscurso, no qual ele se articula por 'co-referência'” (PÊCHEUX, 1995, p. 167), produzindo um efeito, imaginário, de unidade/evidência do sujeito. É de um trabalho de costura que o sujeito faz entre os diferentes recortes discursivos, trazidos do interdiscurso, que está a base da produção do efeito-texto, "um espaço discursivo organizado, simbolicamente fechado e ilusoriamente completo" (INDURSKY, 2015, p. 78). E o sujeito-autor precisa dessas duas ilusões - completude e fechamento - tanto para (se) dizer quanto para dar fecho à costura do seu dizer.

No entanto, assim como uma teia, ou uma "rede de pesca", "os fios são tão relevantes para o processo de fazer sentido, como os furos, por onde a falta, a falha se deixam escoar. Se não houvesse furos, estaríamos confrontados com a completude do dizer", segundo Ferreira (2003, p. 44). Desse modo, a teia dos discursos pode se manter ou se romper a qualquer momento, e, na continuidade dos sentidos, pode haver a resistência, o questionamento, a contradição, o deslocamento, o rompimento, a falha, a partir dos quais se abrem espaços para outros sentidos se produzirem.

Na reescrita do texto, vê-se, nesse sentido, um deslocamento, uma transformação, ou, ainda, uma ruptura na linearidade dos sentidos em que se dá o diferente, o inesperado: o acontecimento. É essa falha no ritual, permeada pelos movimentos de produção do sujeito na história, que impede que os sentidos se reproduzam. Há uma reedição, uma vez que a forma como os fatos se reeditam depende do modo como a história e as condições de produção os apagam e os ressignificam. O sujeito-aluno só se (re)significa a partir do lugar onde se reconhece como tal, sendo que as suas relações com a história e com os sentidos "não podem mais ser tomadas como 'representações` subjetivas que os sujeitos constroem sobre o real, mas, ao contrário, é o campo da prática concreta, da experiência, do vivido, que determina como o real precisa ser representado e significado como discurso" (ZANDWAIS, 2009, p. 27, grifo da autora).

Desse modo, percebe-se, na reescrita, um sujeito fragmentado, dividido e refratário da relação com o outro, sendo este outro cada formação discursiva com a qual dialoga: professores, colegas, instituição etc. Aí se mostra o real da língua, aquilo que não pode ser dito nem previsto, a falha constitutiva da língua (MILNER, 1987), que permite ao sujeito ser e deixar de ser na linguagem, através das relações que constrói a partir do vivido e do significado como discurso em sua relação com o outro e o mundo - e que não são previstos nem fixados, mas (re)significados. 


\section{Considerações finais: um efeito de fecho do analista-professor}

Voltando, enfim, à epígrafe, pergunta-se: de que modo é possível para o analista do discurso (ou, de modo mais amplo, de linguagem) desopacificar para o leitor o sentido do texto? Com base no percurso teórico-analítico deste trabalho, acredita-se que se o professor, enquanto analista de linguagem, considera o leitor o seu aluno, ele pode então promover em sala de aula um processo de produção de textos em que se torna possível prever um movimento de deslocamento de sentidos em que o aluno reconheça, pela mediação da língua, seu lugar de sujeito de/na sua história, que, como tal, transforma-se, desliza, torna-se outro. Inscrito nesse movimento, da escrita à reescrita, o aluno inscreve-se na inter-relação entre sujeito-língua-história que se manifesta no texto, a partir da qual se tecem os sentidos do discurso emergidos pelo efeito-texto e a partir da qual eles são ressignificados.

Esse olhar, como uma categoria de análise, que se pretende lançar sobre o texto, concebido como uma unidade em que circulam movimentos de sentidos que não cabem nele, mas o extrapolam. Não se almeja tão somente saber o que texto quer dizer, mas sim entender como esse texto significa. E, nesse sentido, o analista não tem outra via de acesso ao discurso senão pelo texto, e este é apenas materialidade enquanto efeito - aquilo que transborda do texto na relação entre sujeito e sentido, em que ambos se submetem à experiência e à história, se detendo junto às margens, ao mesmo tempo em que ultrapassam seus limites em direção a outros sentidos mediados pela língua.

Para Indursky (2015, p. 81), “o texto, para a análise do discurso, é um efeito-texto, espaço discursivo, dotado ilusoriamente de homogeneidade e completude, sendo seu fechamento de ordem simbólica" (grifos da autora). No entanto, esse efeito de fechamento não impede a saturação dos sentidos em direção a outros e diferentes sentidos, quando, nesse movimento, revela-se uma "tomada de posição" pela qual o sujeito se contrapõe aos saberes organizados no interior de determinada formação discursiva. Desse modo, o "mau sujeito", na contra identificação, questiona saberes pertencentes à formação discursiva em que ele se inscreve e o faz a partir do interior desta mesma formação discursiva.

Ao se contrapor aos dizeres e aos sentidos que são próprios à FD que o afeta, o aluno institui um gesto de resistência à forma-sujeito e ao domínio de saberes que ela organiza - no caso, a instituição universitária, que significa para o sujeito do discurso, o aluno, as (im)possibilidades de dizer por meio da escrita e da reescrita. E o outro, o professor e os colegas, representa para o aluno essas (im)possibilidades, tendo em vista os lugares sociais 
que ocupam no processo de significação do discurso - de avaliação e autoridade, ou de mediação e interlocução.

Da escrita à reescrita, os sentidos, ao mesmo tempo que se repetem, deslocam-se para sentidos outros, para novas posições na linguagem. Tal mudança é possível pelo fato de que, na reescrita, pelo contato com outras FDs - e dessa forma, com outros saberes -, o aluno desconstrói e reconstrói seus saberes acerca do processo de escrita, o que pode ser identificado pelo processo de subjetivação da reescrita na qual se assinala uma mudança de tomada de posição: uma nova posição-sujeito. Logo, o olhar que reconhece essa possibilidade de mudança (re)significa o estudo do texto em sala de aula.

\section{REFERÊNCIAS}

ALTHUSSER, Louis. Sobre a reprodução. In: A propósito da reprodução das relações de produção. Rio de Janeiro: Editora Vozes, 1999.

BAKHTIN, Mikhail (Volochinov). Marxismo e filosofia da linguagem. In: Estudo das ideologias e filosofia da linguagem. São Paulo: Hucitec, 1986.

COURTINE, Jean Jacques. Análise do discurso político: o discurso comunista endereçado aos cristãos. In: . Orientações teóricas da pesquisa. São Carlos: Editora Edufscar, 2009.

FERREIRA, Maria Cristina Leandro. O quadro atual da Análise de Discurso no Brasil. Letras, PPGL-UFSM, n.27, dez. 2003. p. 39-43.

INDURSKY, Freda. Da interpelação à falha no ritual: a trajetória teórica da noção de Formação Discursiva. In: Roberto Leiser Baronas. (Org.). Análise do Discurso: apontamentos para uma história da noção-conceito de formação discursiva. São Carlos: Pedro \& João Editores, 2007.

. O texto nos limites dos estudos da linguagem: especificidades e limites. In: ORLANDI, Eni; LAGAZZY-Rodrigues (Orgs.). Discurso e textualidade. Campinas: Pontes Editores, 2015.

JUCHEM, Aline. Por uma concepção enunciativa da escrita e re-escrita de textos em sala de aula: os horizontes de um hífen. Dissertação (Mestrado em Estudos da Linguagem). Programa de Pós-Graduação em Letras, Universidade Federal do Rio Grande do Sul, Porto Alegre, 2012.

MILNER, Jean Claude. O amor da língua. Porto Alegre: Artes Médicas, 1987.

MITTMANN, Solange. Discurso e texto: na pista de uma metodologia de análise. In: INDURSKY, F.; FERREIRA, M.C. (Orgs.). Análise do Discurso no Brasil: mapeando conceitos, confrontando limites. São Carlos: Claraluz, 2007.

ORLANDI, Eni P. Ponto final: interdiscurso, incompletude, textualização. In:

Discurso e texto. São Paulo: Pontes, 2001.

. Análise de Discurso: princípios e procedimentos. São Paulo: Pontes, 2007a.

As formas do silêncio: no movimento dos sentidos. SP, Campinas: Editora da Unicamp, 2007b.

PÊCHEUX, Michel. Hacia el análisis automático del discurso. Madrid, Gredos, 1975.

. Semântica e Discurso: uma crítica à afirmação do óbvio. SP, Campinas: Editora da

Unicamp, 1988. 
Por uma análise automática do discurso: uma introdução à obra de Michel Pêcheux. In: GADET, F; HAK, T. (orgs.). Campinas-SP: Editora da Unicamp, 1990.

SCHONS, Carme Regina. Saberes anarquistas: reiterações, heterogeneidades e rupturas. Passo Fundo: Ediupf, 2000.

ZANDWAIS, Ana. Perspectivas da análise do discurso fundada por Michel Pêcheux na França: uma retomada de percurso. Santa Maria: UFSM, 2009.

Recebido em 29/03/2018. Aceito em 06/06/2018. 